\title{
Comparative evaluation of composite and simplified who partograms in a tertiary care centre in North India
}

\author{
Prachi Sarin Sethi $^{1 *}$, Sujata Sharma ${ }^{1}$, Indu Chawla ${ }^{2}$
}

\begin{abstract}
${ }^{1}$ Department of Obstetrics and Gynecology, Government Medical College, Amritsar, Punjab, India
${ }^{2}$ Department of Obstetrics and Gynecology, PGIMER, Dr. R.M.L Hospital, New Delhi, Delhi, India
\end{abstract}

Received: 23 August 2017

Accepted: 16 September 2017

\section{*Correspondence:}

Dr. Prachi Sarin Sethi,

E-mail: prachi.sarin@gmail.com

Copyright: (c) the author(s), publisher and licensee Medip Academy. This is an open-access article distributed under the terms of the Creative Commons Attribution Non-Commercial License, which permits unrestricted non-commercial use, distribution, and reproduction in any medium, provided the original work is properly cited.

\section{ABSTRACT}

Background: Early detection of abnormal progress and prevention of prolonged labour can significantly improve the outcome of labour. Partograph is an inexpensive tool which can provide a continuous pictorial overview of labour and is essential to monitor and manage labour. The objectives were to study the course of normal and abnormal labour and to evaluate the maternal and perinatal outcome using simple and composite WHO partogram.

Methods: This was a randomized study conducted at Department of Obstetrics and Gynaecology, Government Medical College, Amritsar, a tertiary care centre in North India. 200 women with term, singleton, vertex gestation, in spontaneous labor were included in the study. In 100 cases composite partograph was plotted and in rest 100 cases simple partograph was plotted. The following outcomes were compared: labor crossing the alert and action line, augmentation of labor, rate of cesarean section, perinatal and maternal outcome.

Results: The partogram crossed the alert line ( $p$ 0.008) and action lines ( $p$ 0.017), causing increased need for augmentation ( $\mathrm{p}$ 0.034) in the composite partogram which was statistically significant. The numbers of vaginal deliveries were high $(\mathrm{p}<0.001)$ and decrease number of cesarean sections ( $\mathrm{p}$ 0.007) and instrumental deliveries $(\mathrm{p}$ 0.009 ) in the simplified group. NICU admissions were also higher in the composite group ( $\mathrm{p}<0.05$ ), though most of the NICU admissions were due to hyperbilirubinemia and low birth weight and was not directly related to monitoring of labour.

Conclusions: It was observed in the present study that labour can be managed without the latent phase being plotted on the partograph. The interventions were higher when the latent phase was included, with increased number of labours crossing the alert and action lines, increased no. of augmentations and larger number of caesarean sections. Our study favours the use of the WHO modified partograph, which should become routine practice in monitoring labour for better maternal and perinatal outcome.

Keywords: Action line, Alert line, Labour, Partogram

\section{INTRODUCTION}

Labour although is a natural process but complications can arise at any time during its course. Prolongation of labor presents a picture of mental anguish, physical morbidity and may lead to surgical intervention. Mother is exposed to higher risk of infection, dehydration, ketosis, unrecognized obstructed labor and loss of moral. The fetus on other hand is exposed to the dangers of infection, asphyxia, and excessive cranial molding. In developing world, there is higher incidence of maternal and fetal morbidity and mortality due to prolonged labour. Therefore, there is an increase in need for evaluation of usefulness of active management of labour 
and use of partogram in detecting any deviation from normal labour. ${ }^{1}$

One of the tools used to monitor labour and prevent prolonged and obstructed labour is the partograph, a preprinted one-page form on which labour observations are recorded. The purpose of the partograph, also called the partogram, is to help health care providers record, interpret, analyze, and use data to make clinical management decisions while labour is in progress.

WHO has published 3 different types of the partographs since 1990. The WHO composite partograph (1994) which includes a latent phase of 8 hours and an active phase starting at $3 \mathrm{~cm}$ cervical dilatation, the action line is 4 hours to the right of and parallel to the alert line. ${ }^{2}$ But its main drawback was inappropriate interventions if undue attention is paid to the latent phase. Subsequently, in 2000 the WHO produced the modified/simplified partograph where the latent phase was excluded, and the active phase commences at $4 \mathrm{~cm}$ dilatation (to reduce interventions in multiparous women with patulous cervices not yet in labour and to make it simpler and easier to use). ${ }^{3}$

This comparative study intends to compare two World Health Organization (WHO) partographs - a composite partograph including latent phase with a simplified one without the latent phase and to further evaluate the usefulness in detecting abnormal labour and the effect on perinatal outcome of the two partographs.

\section{METHODS}

The present study was conducted on primigravidas and multipara admitted in the labour room of Department of Obstetrics and Gynaecology, Shri Guru Tegh Bahadur Hospital attached to Govt. Medical College, Amritsar, a tertiary care centre in North India. This study included 200 patients, divided into two groups after recording and matching baseline characteristics.

Group (A) included those cases for which composite partogram were plotted.

Group (B) included those cases for which modified/simplified partogram was plotted.

All women with uncomplicated, singleton, term, vertex gestations, in spontaneous labor were included in the study. Each participant was informed about the purpose of the study and was required to sign an informed consent. Either partograph was used for monitoring of labour. Exclusion criteria included women with short stature $(<140 \mathrm{~cm}$.$) , antepartum haemorrhage, severe$ preeclampsia / eclampsia, anaemia, malpresentations, multiple pregnancy, previous caesarean section, preterm labor, fetal distress and intrauterine death. The partograph was started after establishment of true labor defined as the presence of good uterine contractions (3 in 10 minutes of 40-45 seconds). The plotting of the composite partograph was started as soon as the woman was in labor. In the simplified partograph, the plotting of the partograph was started with $\geq 4 \mathrm{~cm}$ of cervical dilatation. Labor was monitored until delivery. The outcome was reported at the bottom of each partograph. The outcomes noted were labors crossing the alert and action line, augmentation of labor, rate of cesarean section, perinatal outcome and maternal complications.

\section{Statistical analysis}

Mean and Standard deviation was calculated for quantitative variables like Age, BMI and Period of gestation and independent sample t-test was used to compare these variables. Chi-Square was used to compare variables like parity, partograph crossing alert line, partograph crossing action line, patients where augmentation was required, mode of delivery, indication for caesarean section, maternal and perinatal outcome. $\mathrm{p}$ value was obtained. $\mathrm{p}$ value $<0.05$ was considered as significant and $\mathrm{p}$ value $<0.001$ was considered to be highly significant.

\section{RESULTS}

A total of 200 cases who fulfilled the inclusion criteria were enrolled in the study, of which 100 cases were randomised to composite partograph group, and the other 100 to modified partograph group.

Table 1: Patient characteristics in composite and simplified partogram.

\begin{tabular}{|llll|}
\hline Variable & Composite & Simplified & P value \\
\hline $\begin{array}{l}\text { Mean age } \\
\text { (years) }\end{array}$ & $25.02+3.08$ & $25.62+3.99$ & 0.236 \\
\hline $\begin{array}{l}\text { Mean BMI } \\
\left(\mathrm{kg} / \mathrm{m}^{2}\right)\end{array}$ & $21.41+1.158$ & $21.41+1.18$ & 0.995 \\
\hline $\begin{array}{l}\text { Primigravida } \\
\text { Multipara }\end{array}$ & 56 & 54 & 0.776 \\
\hline $\begin{array}{l}\text { Mean period } \\
\text { of gestation }\end{array}$ & $38.12+0.76$ & $38.02+0.74$ & 0.836 \\
\hline
\end{tabular}

Majority of the patients in the study had mean age of 25 years. There was no statistical difference in the age of the patients between the two groups $(\mathrm{p}=0.236)$. The minimum age in composite group was 20 years and in simplified was 19 years while the maximum was 33 yrs in composite and $35 \mathrm{yrs}$ in modified partograph groups (Table 1).

The average BMI of the women in both the simplified and modified partogram group was found to be 21.4 $\mathrm{kg} / \mathrm{m} 2$. This was also not statistically significant. $(\mathrm{p}=0.995)$ (Table 1).

The study included both primigravida and multipara. In the Composite partogram group, the number of primigravida were 56 and multipara were 44 , however in 
simplified group it was 54 and 46 respectively and was not statistically significant ( $\mathrm{p}=0.776$ ) (Table 1$)$. The mean gestational age in the composite partogram group was 38 weeks and in the simplified group was 38 weeks 1 day.
This was statistically not significant in both the groups $(\mathrm{p}=0.836)$ (Table 1). There was no significant difference between the mean birth weight of babies in group A and group B.

Table 2: Comparison of labour outcomes in composite and simplified partogram.

\begin{tabular}{|c|c|c|c|}
\hline Variable & Composite $(\mathrm{N}=\mathbf{1 0 0})$ & Simplified (N=100) & P value \\
\hline Labours crossing alert line & 32 & 16 & 0.008 \\
\hline Labours crossing action line & 10 & 2 & 0.017 \\
\hline Labours where augmentation was required & 32 & 15 & \multirow{4}{*}{0.034} \\
\hline ARM & 7 & 5 & \\
\hline ARM+Oxytocin & 19 & 8 & \\
\hline Oxytocin & 6 & 2 & \\
\hline \multicolumn{4}{|l|}{ Mode of delivery } \\
\hline Vaginal delivery & 68 & 90 & $<0.001$ \\
\hline Instrumental delivery & 9 & 1 & 0.009 \\
\hline Caesarean section & 23 & 9 & 0.007 \\
\hline \multicolumn{4}{|l|}{ Maternal outcome } \\
\hline Post partum haemorrhage & 1 & 0 & \multirow{2}{*}{0.316} \\
\hline Puerperal sepsis & 0 & 0 & \\
\hline Admission to NICU & 15 & 3 & 0.003 \\
\hline Apgar Score $<7$ at 5 minutes & 1 & 1 & 1 \\
\hline
\end{tabular}

Table 3: Indication of caesarean section.

\begin{tabular}{|c|c|c|c|}
\hline Indication & $\begin{array}{l}\text { Composite } \\
(\mathrm{N}=100)\end{array}$ & $\begin{array}{l}\text { Simplified } \\
(\mathrm{N}=100)\end{array}$ & $\begin{array}{l}p \\
\text { value }\end{array}$ \\
\hline Fetal distress & 19 & 8 & \\
\hline $\begin{array}{l}\text { Non- } \\
\text { progress of } \\
\text { labour }\end{array}$ & 4 & 1 & 0.016 \\
\hline
\end{tabular}

The partogram crossed the alert line ( $\mathrm{p}$ 0.008) and action lines ( $p$ 0.017), causing increased need for augmentation ( $p$ 0.034) in the composite partogram which was statistically significant (Table 2). The numbers of vaginal deliveries were high $(\mathrm{p}<0.001)$ and decrease number of cesarean sections ( $\mathrm{p}$ 0.007) and instrumental deliveries ( $\mathrm{p}$ 0.009 ) in the simplified group (Table 2). Most common indication of caesarean section was fetal distress followed by non-progress of labour (Table 3). NICU admissions were also higher in the composite group $(\mathrm{p}<0.05)$, though most of the NICU admissions were due to hyperbilirubinemia and low birth weight and was not directly related to monitoring of labour (Table 4). However, there was no significant difference in the maternal outcome in the two groups (Table 2).

Table 4: Indication for NICU admission.

\begin{tabular}{|c|c|c|c|}
\hline Indications & Composite & Simplified & p value \\
\hline Hyperbilirubinemia & 9 & 2 & \multirow{3}{*}{0.03} \\
\hline Low birth weight & 5 & 1 & \\
\hline Meconium aspiration syndrome & 1 & 0 & \\
\hline
\end{tabular}

\section{DISCUSSION}

The present study was undertaken to highlight as to which WHO partograph is associated with better labour outcome and so that its usage becomes a routine practice in all health setups. Age and BMI plays an important factor in determining the obstetrical outcome. It can have an impact on pregnancy at both the ends of reproductive spectrum. Teenagers are more likely to be anaemic and can have a low BMI having more chances of preterm deliveries, growth restricted infants and higher infant mortality while woman more than 35 yrs of age and high BMI has chances of diabetes, hypertension, placenta previa, abruption and perinatal mortality. The mean age and BMI in the study is favourable for conception and least pregnancy related complications. 
Difference in age, BMI, parity and gestational age were seen to be not significant in both the groups, therefore they did not act as confounding factors for the results (Table 1).

Partogram crossing alert line was found in $32 \%$ of cases in the composite partograph group and $16 \%$ of patients in the modified partograph group $(\mathrm{p}=0.008)$ which was statistically significant. The study is in concordance with the Belgaum study where $28.2 \%$ and $13.98 \%$ crossed the alert line in the two groups respectively. ${ }^{4}$ It was observed that $23.6 \%$ of patients crossed the alert line when the composite partograph was plotted in a study conducted in Indonesia. ${ }^{5}$ Similar observations were made at Vellore study where $17.7 \%$ and $15.1 \%$ of partogram crossed alert line in the two groups respectively. ${ }^{6}$ A study done in Pakistan showed $11.6 \%$ of partogram to cross the alert line in the modified partograph group. ${ }^{7}$

Partogram crossing the action line was observed in $10 \%$ and $2 \%$ parturients in the composite and modified groups respectively ( $\mathrm{p}$ value $=0.017$ ) which was statistically significant. The study was in concordance with the Vellore study where labour had crossed the action line in $7 \%$ in the composite group as compared to $1 \%$ in the modified group. ${ }^{6}$ Similar observations were reported in the Belgaum study where $10.8 \%$ and $1.96 \%$ cases crossed the action line in the two groups respectively. ${ }^{4}$

Augmentation of labour was required in 32 cases who were randomized to the composite partograph as compared to 15 in the simplified group which was again statistically significant $(\mathrm{p}$ value $=0.034)$. Similar results were reported in the Belgaum study where augmentation was $36.6 \%$ and $16.8 \%$ in the two groups respectively. ${ }^{4}$ In the present study oxytocin was used in $25 \%$ in composite group and $10 \%$ in modified partograph group. In the Vellore study, augmentation with oxytocin was done in $23.8 \%$ and $21.8 \%$ in both the groups respectively. ${ }^{6}$ Also, similar results were observed in a study done at Calcutta, where it was $19.4 \%$ and $10.6 \%$ in composite and modified group respectively. ${ }^{8}$ In a study done at Indonesia oxytocin was used in $16 \%$ of cases in composite partograph group. ${ }^{5}$

In the present study vaginal delivery success rate was $68 \%$ in the composite group and $90 \%$ in the modified partograph group $(\mathrm{p}<0.001)$. This was statistically highly significant. The study at Belgaum reported $75.7 \%$ and $89.25 \%$ respectively which is in concordance with our study. ${ }^{4}$ Similar results were observed in the Vellore study where $78.8 \%$ and $86.5 \%$ underwent vaginal delivery in both the groups respectively. ${ }^{6}$ The results were also similar to the study done at Calcutta which showed $80.6 \%$ vaginal delivery in the composite group and $82.7 \%$ in the modified group. ${ }^{8} 9 \%$ and $1 \%$ of the cases had instrumental delivery in composite and modified partograph groups respectively making it statistically significant ( $\mathrm{p}$ value $=0.009$ ). The results were similar to the study at Vellore where instrumental delivery was in
$7 \%$ and $9 \%$ in both the groups respectively. ${ }^{6}$ Also the reports were in concordance with the study at Calcutta, where $9.3 \%$ and $8.33 \%$ of patients underwent instrumental delivery. ${ }^{8}$ Similar results were reported in the Belgaum study where the rate was $6.8 \%$ and $6.7 \%$ respectively. ${ }^{4}$

In the present study $23 \%$ and $9 \%$ in the composite and modified partograph groups respectively underwent caesarean section ( $\mathrm{p}$ value $=0.007$ ). The results were statistically significant. The results were in accordance to Belgaum study where caesarean section rate was $23.9 \%$ and $10.08 \%$ in the two groups respectively. ${ }^{4}$ The study at Calcutta had $10 \%$ and $8.9 \%$ caesarean section rate in composite and modified partograph groups respectively. ${ }^{8}$ The Vellore study showed only $12.6 \%$ and $3.2 \%$ of parturients undergoing caesarean section. ${ }^{6}$ The higher rate of caesarean section in our study could be due to early decision to operative interference in certain situations. Maximum numbers of caesarean sections were due to fetal distress, seen in 19\% of composite partograph and $8 \%$ of modified partograph group. This was seen to be statistically significant $(\mathrm{p}$ value $=0.016)$.

Apgar score $<7$ at 5 minutes was $1 \%$ in both the composite and modified partograph groups which was not statistically significant ( $\mathrm{p}$ value $=1$ ). Both the babies were admitted to NICU. One baby was shifted to mother side on day- 5 and the other on day-7. No further serious consequences were observed in both. There was statistically significant difference in the number of infants admitted to NICU which was $15 \%$ and $3 \%$ in the composite and modified partograph groups respectively ( $\mathrm{p}$ value $=0.003$ ). Out of $15 \mathrm{NICU}$ admissions in the composite partograph 9 were due to Hyperbilirubinemia, 5 due to low birth weight and 1 due to meconium aspiration syndrome in composite partograph. In the simplified WHO partograph out of 3 NICU admissions, 2 were because of hyperbilirubinemia and only 1 was due to low birth weight ( $\mathrm{p}$ value $=0.03$ ). Therefore, it was observed that NICU admission was not due to any labour monitoring.

\section{CONCLUSION}

The present study concluded that the modified partograph is better than the composite one based on the following observations.

- Labour values crossed the alert and the action lines significantly more often when composite partograph was used.

- Composite partograph led to increased rate of augmentation which was statistically significant.

- Rate of cesarean section was significantly less when modified partograph was used.

- The success rate in terms of vaginal delivery was more with modified partograph and was statistically highly significant. 
- NICU admissions were also less when modified partograph was used, though it was not related to the monitoring of labour and the main causes of NICU admissions was hyperbilirubinemia and low birth weight.

- However, there was no significant difference in terms of maternal complications such as PPH and puerperal sepsis or in perinatal outcome i.e. Apgar score $<7$ at 5 minutes between the two groups.

Thus, ideally the patients with no high-risk factors should be admitted to labour room only at active phase of labour. This not only reduces unnecessary interventions, per vaginal examinations, undue anxiety and tension but also increases early ambulation. It also reduces the labour room bed occupancy rate, decreases augmentation and cesarean section, and increases the doctor: patient ratio and nursing staff: patient ratio, thus providing better patient care.

Hence efforts should be made to implement the routine use of WHO modified partograph at all levels especially the primary and secondary healthcare levels for better labour outcomes.

\section{ACKNOWLEDGMENTS}

Authors would like to acknowledge Dr. Sujata Sharma, Head of Department, Department of Obstetrics and Gynecology, Government Medical College, Amritsar for the completion of the present task. Authors are also grateful to Dr. Indu Chawla, Senior Specialist, Department of Obstetrics and Gynecology, PGIMER, Dr. R.M.L Hospital for her immense support and help in carrying out this study.

Funding: No funding sources Conflict of interest: None declared

Ethical approval: The study was approved by the Institutional Ethics Committee

\section{REFERENCES}

1. O Driscoll K, Stronge JM, Minogue M. Active management of labour. British Med J. 1973;3:135-8.

2. World Health Organisation. World Health Organisation partograph in the management of labour. Lancet. 1994;343:1399-1404.

3. Mathai, Matthews. The partograph for the prevention of Obstructed Labour, Lippincott Williams and Wilkins. 2009;52(2):256-69.

4. Kenchaveeriah SM, Patil KP, Singh TG. Comparison of two WHO partographs: a one year randomized controlled trial. J Turkish-German Gynecol Assoc. 2011;12(1):31-4.

5. Fahdhy M, Chongsuvivatwong V. Evaluation of World Health Organization partograph implementation by midwives for maternity home birth in Medan, Indonesia. Midwifery 2005;21(4):301-10.

6. Mathews JE, Rajaratnam A, George A, Mathai M. Comparison of two World Health Organization partographs. Int J Gynecol Obstet. 2007;96(2):14750.

7. Javed I, Bhutta S, Tabassum S. Role of partograph in preventing prolonged labour. J Pak Med Assoc. 2007;57:408.

8. Alauddin Md, Bal R, Arunangsu De, Mandal P, Chakraborty P. Monitoring of labor with WHO modified partograph: a study report. NJOG. 2008;3:8-11.

Cite this article as: Sethi PS, Sharma S, Chawla I. Comparative evaluation of composite and simplified who partograms in a tertiary care centre in North India. Int J Reprod Contracept Obstet Gynecol 2017;6:5003-7. 